This is the 'post-print' version (accepted following the referee process) of this paper in accordance with the Green Access standard for this journal

Oxbrough, A. G., Gittings T., O'Halloran J., et al. 2007. Biodiversity of the ground-dwelling spider fauna of afforestation habitats. Agriculture Ecosystems and Environment: 120, 433-441.

\title{
Biodiversity of the ground-dwelling spider fauna of afforestation
}

\author{
habitats
}

Anne G. Oxbrough*, Tom Gittings, John O’Halloran, Paul S. Giller, Tom C Kelly

Department of Zoology, Ecology and Plant Science, Cooperage Building, University College

Cork, Distillery Fields, North Mall, Cork, Ireland

*Corresponding author. E-mail address: a.oxbrough@hotmail.com

Tel +353214904677

$15 \quad$ Fax +353214904664 


\begin{abstract}
The aim of this study was to assess spider diversity among habitats that are typically used for afforestation in Ireland, and to identify habitat parameters which could potentially be used as indicators of their biodiversity value. Ground-dwelling spiders were surveyed in 24 sites across

5 Ireland, with eight sites of each of the following habitat types: improved grassland, wet grassland and peatland. The spiders were sampled using pitfall traps which were located within the major vegetation types present in each site as well as within supplementary habitat features which may add to biodiversity value of the whole site such as hedgerows, flushes and the edges of ditches and streams.
\end{abstract}

Each habitat supported distinct spider assemblages that reflect major differences in both environmental conditions and management regime. The improved grasslands had low spider species richness and low variation in assemblage structure which is probably related to the intensive management of this habitat. In this case hedgerows maybe an important aspect of the spider diversity within agricultural landscapes. The peatlands, and to a lesser extent wet grasslands, supported a diverse and specialist spider fauna, including a number of rare species; this may be due to differences in soil moisture and plant architecture. Indicators of biodiversity value identified included wet flushes in the peatlands and low grazing pressure in the wet grasslands. This study suggests that in terms of biodiversity value improved grassland is the preferable habitat for afforestation, because of the poor baseline spider diversity. However it may be unrealistic to expect land owners to afforest their most productive agricultural land, so the management and habitat indicators identified in this study may be of use for assessing habitat quality among the wet grassland and peatlands to allow sites with lower biodiversity value to be identified. 
Keywords: Spider assemblages; Biodiversity; Indicator; Peatland; Grassland; Afforestation; Hedgerow 


\section{Introduction}

In recent years the expansion of European forests can be largely accounted for by the afforestation of former agricultural land (UNECE, 2003). In Ireland, 10.2\% of the total land area is currently under forestry (Forest Service, 2004), however the Irish government ultimately aims to achieve a forest cover of $17 \%$ (COFORD, 2000). Although there has been a virtual cessation in state-owned afforestation in recent years, the growth of the private forest sector has continued with annual planting of 9600 ha per year, accounting for $99 \%$ of all Irish afforestation (Forest Service, 2004). The introduction of incentive schemes such as the Forest Farm Partnership, which provides farmers with annual premiums for establishing plantations on their land, has meant that $90 \%$ of the total afforestation is now accounted for by agricultural land owners (Teagasc, 2005). Less productive agricultural land may be more readily selected by landowners for afforestation, however areas with lower productivity, usually those which are less intensively managed, are often those which contribute the most to biodiversity within the agricultural landscape (Downie et al., 1999; Cole et al., 2003).

In order to evaluate the potential species loss or gain caused by afforestation it is first necessary to establish what species are present in a given habitat. The use of biodiversity indicators in habitat quality assessments have gained increasing importance in recent years (Paoletti, 1999; Duelli and Obrist, 2003), with the recognition that for most groups of animals and plants the resources are not available to carry out complete inventories of the species present. Spiders have been used as indicators of invertebrate diversity (Gravesen, 2000; Cardoso et al., 2004), probably because of their predatory position in food webs and their relationship with vegetation structure, which can be linked to changes in environmental conditions.

The aim of this study was to investigate the diversity of ground dwelling spiders among several habitats typically used for afforestation in Ireland and to identify key features within these 
habitats which could potentially be used as indicators of their biodiversity value. This research will also provide valuable information on the distribution and ecology of spiders in several major Irish habitats which has been lacking in the past.

\section{Study areas and methods}

Three habitat types were selected for the study based on recent afforestation trends in Ireland (Forest Service, unpublished data); improved grassland, wet grassland and peatlands. Within each habitat type there were eight sites surveyed which represented a wide geographical spread of the habitats across Ireland. The improved grasslands were generally on well drained brown earth or brown podzolic soils, ranging in elevation from 45-300m, and were heavily grazed. They were dominated by Lolium perenne but also often with some Trifolium repens, Holcus lanatus and Cynosurus cristatus. The wet grasslands were typically on moderately drained gley soils, ranging in elevation from 45-175m and were generally under low-moderate grazing pressure. Juncus acutiflorus, Juncus effusus, H. lanatus and Agrostis stolonifera were abundant in most sites although two sites had a high cover of Molinea caerulea. The peatlands were generally on poorly drained peat or peaty podzolic soils which ranged in elevation from $20-250 \mathrm{~m}$ with lowmoderate grazing. Typical plant species included M. caerulea, Calluna vulgaris, Eriophorum angustifolium and Eriophorum vaginatum and mosses, especially Sphagnum species.

Spiders were sampled using pitfall traps that consisted of a plastic cup $7 \mathrm{~cm}$ in diameter by $9 \mathrm{~cm}$ in depth. A bulb corer was used to make a hole in the ground for the plastic cup, which was placed so that the rim of the cup was flush with the grounds' surface. In the sites which were heavily grazed (mostly improved grassland) a section of plastic piping $(7 \mathrm{~cm}$ diameter by $10 \mathrm{~cm}$ depth), was inserted into the ground, and the plastic cup then inserted within this ring to protect it from trampling. Each plastic cup had two drainage slits cut $1 \mathrm{~cm}$ from the rim of the cup and were filled to $1 \mathrm{~cm}$ depth with ethylene glycol. 
Within each site six sampling plots were established (three 'standard' and three 'supplementary' plots) each plot being separated by a minimum of $50 \mathrm{~m}$. Standard plots were located in areas of homogenous vegetation cover that encompassed the major types of vegetation cover present within each site. These plots consisted of five pitfall traps which were arranged in a $4 \times 4 \mathrm{~m}$ grid, with one trap at each corner and one in the centre. The supplementary plots were located in additional features which may contribute to biodiversity of the site as a whole. In the grasslands all of the supplementary plots sampled were located in hedgerows, whereas in the peatlands the supplementary plots were located in wet flushes, however in sites where these were not present linear features such as the edges of ditches and streams were sampled to adequately represent the diversity of microhabitats present. For plots in linear features (hedgerows, edges of ditches and streams) the five pitfall traps were arranged in a line, each trap being placed $2 \mathrm{~m}$ apart along the feature.

This resulted in a total of 48 plots per habitat type and 144 plots in total across the study. For logistical reasons fieldwork was carried out over two field seasons (May-July) in 2002 and 2004 in the following arrangement: peatland: (4 sites in 2002, 4 in 2004); wet grassland (2 sites in 2002, 6 in 2004); improved grassland: ( 2 sites in 2002, 6 in 2004). The traps were active for between 63-65 days and were changed three times during this period, approximately every 21 days. In five of the sites a large number of traps were lost through trampling and so the pitfall traps were maintained for an extra 21 days in these sites.

Pitfall samples were stored in $70 \%$ alcohol and the spiders were sorted from the catch. Identification of spiders to species level was carried out using a x50 magnification microscope and nomenclature follows Roberts (1993). The lack of research carried out on spiders in Ireland means that it can be difficult to determine if species are genuinely rare or just under recorded. Therefore the Provisional Atlas of British spiders (Harvey et al., 2002) was used in conjunction 
with Irish records (van Helsdingen, 1996a, 1996b; McFerran, 1997; van Helsdingen, 1997; Nolan, 2000a; Cawley, 2001; Nolan, 2002a, 2002b; Fahy and Gormally, 2003) to determine species rarity. Species which occurred in less than five of the Irish counties and which were designated as either Nationally Scarce or are recorded as Red Data Book species in Great Britain (Bratton, 1991) were considered to be rare. The species were assigned to habitat associations using the literature, based on their preference for the following habitat and microhabitat characteristics: general habitat preference (open habitats, forested habitats or generalists), moisture preference (wet habitats, dry habitats or generalists) and vegetation preference (ground layer, low vegetation, bushes and trees or generalists).

\subsection{Environmental variables}

The percentage cover of vegetation was recorded in $1 \mathrm{~m}^{2}$ quadrats surrounding each pitfall trap. The vegetation was classified into the following structural layers: ground vegetation $(0-10 \mathrm{~cm})$, lower field layer $(>10-50 \mathrm{~cm})$ and upper field layer $(>50-200 \mathrm{~cm})$. Cover of other features such as deadwood, leaf litter and soil were also recorded. All cover values were estimated using the Braun-Blanquet scale (Mueller-Dombois and Ellenberg, 1974), which involves giving numerical rankings to a range of percentages $(+=<1 \%$ cover; $1=1-5 \% ; 2=6-25 \% ; 3=26-50 \% ; 4=51-$ $75 \% ; 5=76-100 \%)$. The main vegetation species present within each plot were also recorded and each plot was classified by habitat type according to the Irish habitat classification scheme (Fossitt, 2000). At two locations within each plot soil samples were taken using a bulb corer which extracted the top layer of substrate to a depth of $15 \mathrm{~cm}$. Organic content of the soil was calculated using the method outlined in Grimshaw (1989, pp. 12 - 14).

\subsection{Data Analysis}

Traps from the extra trapping period were used, as required, to replace traps lost during the first three sampling periods. If, after replacing lost traps, plots still had three or more traps lost (out of a possible 15), these plots were excluded from the analyses. A mixed model ANOVA was used 
to identify trends in mean species richness, abundance and dominance per plot within each site with habitat type and plot type (standard/supplementary) as fixed factors and site as a random factor nested within habitat type. Dominance was calculated using the Berger-Parker index (Berger and Parker, 1970), where $\mathrm{d}=\mathrm{Nmax} / \mathrm{N}$ (Nmax is the number of individuals in the most abundant species and $\mathrm{N}$ is the total number of individuals). The index ranges from $0-1$, with one indicating the complete dominance of the most abundant species.

To examine general trends in spider assemblage structure within and among the habitat types Global Non-metric Multi-dimensional Scaling (NMS) was used with the following parameter set-up: 6 axes; 20 runs with real data; stability criterion $=0.001 ; 10$ iterations to evaluate stability; 250 maximum iterations; step down in dimensionality used; initial step length $=0.20$; Random starting coordinates; 50 runs of the Monte Carlo test. Flexible-beta cluster analysis (with $\beta=-0.25$ ) and Indicator Species Analysis (Dufrene and Legendre, 1997) was used to examine these trends in more detail. Indicator Species Analysis involves combining the relative abundance and relative frequency of species within a priori groups to give an indicator value which is tested for significance with a Monte Carlo test. Only maximum indicator values with a $\mathrm{p}$ value $<0.01$ were considered significant. These analyses were carried out using relative abundance (the proportion of each species within a sampling plot) rather than absolute abundance as variation in vegetation cover among the habitat types may affect the efficiency of pitfall traps (Melbourne, 1999).

20 To identify potential indicators of spider biodiversity within and among the habitat types investigated Pearson's correlation analyses were used to investigate the relationship between habitat and species variables. For the analyses of habitat variables the appropriate median percentage cover value was substituted for the Braun-Blanquet value from each quadrat, and the mean value was calculated from the five quadrats within each plot. One-way ANOVA with 
Tukey's post-hoc tests were used to analyse trends among the spider assemblages in relation to grazing intensity and the habitat types according to Fossitt (2000). All variables were tested for normality and homogeneity of variance before the use of parametric statistics. Bonferroni corrections were applied to ANOVA and correlation analyses to account for the possibility of making Type I errors when multiple tests are carried out. The environmental variables and Berger-Parker index were arcsin transformed prior to analysis. ANOVA and correlation analyses were carried out using SPSS (SPSS 2002) and multivariate analyses (NMS, cluster analysis and Indicator Species Analysis) were carried out using PC-ORD (McCune and Mefford, 1997).

\section{Results}

Almost $16 \%$ of the traps were lost, most of these within the improved grassland sites. This was mainly due to animal disturbance (cattle trampling) although some were lost through flooding. With these plots excluded, there were a total of 122 plots used in the analyses: 45 plots in the peatlands, 41 plots in the wet grasslands, and 36 plots in the improved grasslands. A total of 20,308 individuals from 173 spider species were captured; of these 1823 were juveniles which were excluded from the analyses. Within the peatland sites 8196 adults in 136 species were sampled, in the wet grasslands there were 5676 adults in 114 species and in the improved grasslands there were 4614 adults in 91 species. There were 37 species associated with open habitats and 12 associated with forested habitats, whereas 52 species sampled had a preference for wet habitats and two species had a preference for dry habitats. There were 105 species sampled that have a preference for the ground layer, 30 associated with low vegetation and two with shrubs.

Among the habitat types the majority of the species variables did not differ significantly, however total richness was lowest in the improved grasslands, whereas species associated with the ground layer were sampled in their highest numbers in this habitat (Table 1). Between the plot types there was more open-associated and wet-associated species supported in the standard 
plots, whereas there were a greater number of forest-associated species sampled in the supplementary plots, although these differences were less noticeable in the peatland habitat. Total richness and abundance however did not differ significantly.

Preliminary analyses indicated that the spider assemblages in the peatlands were distinguished from those in the grasslands and therefore these habitats were analysed separately. A threedimensional solution was recommended from the NMS ordination of the grasslands which accounted for $66 \%$ of the variation in the species data (Figure 1). Axis 1, which accounted for $26 \%$ of the variation, distinguished the spider assemblages by habitat type whereas Axis 2, which accounted for $20 \%$ of the variation, separated the spider assemblages of the standard and supplementary (hedgerow) plots. In general there was much greater variation in assemblage structure among the supplementary plots compared to the standard plots, with the standard plots distinguished much more clearly by habitat type. However, among the standard plots, there was little variation in the assemblage structure of the improved grasslands, whereas the supplementary plots of both habitats varied to a similar degree. Axis 3, which accounted for a further $20 \%$ of the variation in the species data, did not however, represent any trends in assemblage structure among the plot or habitat types.

Three ordination axes were recommended to best explain the trends in the spider assemblages among the peatland plots, which together accounted for $84 \%$ of the variation (Figure 2). Axis 1 , which accounted for $47 \%$ of the variation, broadly distinguished the supplementary plots from the standard plots, however these differences were much less pronounced than among the grassland plots (Figure 1). The majority of the linear supplementary plots (edges of streams and ditches) were separated from the supplementary flushes and also standard plots in poor fen and flush habitat, which formed a distinct cluster of plots. Axis 2, which accounted for $18 \%$ of the variation, broadly distinguished the spider assemblages by habitat type, separating the upland 
blanket bog and wet heath plots from the other peatland habitats, especially the cutover bogs. Cover of ground vegetation was associated with the wet heath and upland blanket bogs, whereas cover of lower field layer vegetation was associated with cutover bogs and linear supplementary plots in lowland blanket bogs (stream edges). Axis 3 accounted for a further $19 \%$ of the variation in the species data and separated those linear supplementary plots with a high cover of upper field layer vegetation from those without.

Cluster analysis revealed four main groups of spider assemblages which were separated by both habitat and plot type. The Peatland-Open assemblage group ( $\mathrm{n}=42$ plots) contained the majority of the standard peatland plots together with some of the standard wet grassland plots. The Improved grassland-Open assemblage group $(n=20)$ consisted solely of the improved grassland standard plots. The Wet grassland assemblage group $(n=16)$ contained most of the wet grassland supplementary and standard plots whereas the Linear assemblage group $(n=44)$ consisted predominately of supplementary plots from all three habitat types, however these plots were all located in linear features (i.e. hedgerows, ditches or streams).

The most indicator species identified were in the Peatland-Open assemblage group (Table 2a), five of which were associated with wet habitats and five associated with open habitats. In the Linear assemblage group six indicator species were identified, two of which were associated with forested habitats. The Improved grassland-Open assemblage group was characterised by species associated with open habitats, whereas in the Wet grassland assemblage group only two indicator species were identified, both of these being associated with wet habitats. The most rare species were sampled in the Peatland-Open assemblage group, four of these being associated with wet habitats (Table 2b). There were, however, no rare species sampled in the Improved grassland-Open assemblage group. 
Among the peatland plots (classified by the Irish habitat guidelines, Fossitt, 2000), measures of species richness and abundance were generally highest in the upland and lowland blanket bogs and lowest in the cutover bogs (Table 3).

Within the Peatland-Open assemblage group, species richness measures were negatively correlated with cover of ground vegetation and positively correlated with cover of lower-field layer vegetation, (Table 4), whereas abundance and dominance showed the opposite trend. In the Linear assemblage group both total richness and abundance were negatively related to cover of the upper field layer vegetation. In the Improved grassland-Open assemblage group species associated with the ground layer were positively correlated with cover of ground vegetation and negatively correlated with cover of lower field layer vegetation whereas in the Wet grassland assemblage group species associated with low vegetation showed the opposite trend.

The species variables within each grazing category are shown in Table 5, however due to the large number of traps lost it was only possible to carry out these analyses within the wet grasslands. Grazing intensity generally had a negative effect on species richness, abundance and richness of the wet habitat specialists as well as number of species associated with ground layer and low vegetation, however the dominance index did not differ with grazing intensity.

\section{Discussion}

The spider assemblages were differentiated among the habitats investigated, with the improved grasslands being particularly distinct from the peatland and wet grassland in terms of species composition, lower species richness and lack of rare species. This is consistent with other studies which compare intensively managed grasslands with semi-natural ones (Downie et al., 1999; Cole et al., 2003) and probably reflects differences in management regime (i.e. grazing and mowing intensity, chemical application, management history) and habitat factors (i.e. cover of vegetation, soil type and soil moisture). 
The improved grasslands were subject to relatively intensive grazing, but also periodic fertilisation and reseeding. Intensive grazing leads to the suppression of vegetation and there has been extensive research on the negative effect of this ground dwelling spider communities (Dennis et al., 1998, 2001; Downie et al., 1999; Cole et al., 2003). Habitat structure (and hence vegetation structure) is the primary factor influencing spider communities; for instance vegetation structure is architecturally important for web builders and aids the concealment of active hunters (see Uetz, 1991 for a review). In the present study the improved grasslands exhibited little variation in assemblage structure and were characterised by ubiquitous, opportunistic species such as E. atra, E. dentipalpis, and $O$. fuscus.

Among the habitat types, general differences in environmental conditions are likely to have a substantial effect on spider species composition. For instance, the habitat types represented a broad gradient in soil moisture from the improved grasslands on relatively dry soils to the peatlands on much wetter soils. Soil moisture has been found to positively influence spider density (Kajak et al., 2000), whereas Usher (1992) found spider assemblage structure was influenced by a wet-dry gradient. This may account for the higher number of specialist wetland species supported in the peatlands and to a lesser extent the wet grasslands in the present study, which included both common species (S. elegans, P. piraticus, A. elegans, G. dentatum) and rare species (S. britenni, S. diceros, M. sublestus). Furthermore, soil moisture may also indirectly affect the spider fauna through its influence on the vegetation species present (Cattin et al., 2003).

Considering the influence of vegetation structure on ground dwelling spider assemblages it is unsurprising that the spider fauna differed among the standard and hedgerow supplementary plots in the grasslands. The hedgerows surveyed exhibited considerable variation in the plant species composition, which included hawthorn (Crataegus monogyna), willow (Salix sp.) and 
ash (Fraxinus excelsior) and also in structure with substantial variation in the understorey layer such as bramble cover (Rubus fruticosus agg), and varying hedgerow widths (1-15m, personal observation). The hedgerows were characterised by more generalist species than the standard plots, although in the wet grassland hedgerows several specimens of the rare species $S$. diceros were sampled, a species which is known to be associated with wet habitats (Harvey et al., 2002). Similarly, Toft and Lovei (2000) found that hedgerows support open generalist species rather than specialists. However, the lack of diversity within improved grasslands in general, may mean that hedgerows constitute a large part of the spider diversity within the agricultural landscape.

The spider assemblages in the peatland supplementary plots did not form a distinct group from the standard peatland plots. Rather, these supplementary plots were separated into two groups, most of the linear plots (edges of ditches and streams) were more similar to the hedgerow plots whereas most of the flushes were more similar to the peatland standard plots. In this case, the spider fauna in supplementary peatland plots may be responding to differences in plant structure and soil moisture. The edges of streams and in particular the ditches may have a more complex vegetation structure due to the protection from grazing afforded by steep banks. In addition to this the ditches and streams, though possibly affected by temporary flooding may otherwise remain relatively dry. In contrast, flushes by definition are directly influenced by ground water. This could be especially important in the peatlands where there are fine-scale patterns in microtopography and moisture that correspond with vegetation zonation.

\subsection{Indicators of biodiversity value}

There was generally a greater variety of habitats within the peatlands than within grasslands as defined using the Guide to Habitats in Ireland (Fossitt, 2000): upland blanket bogs, lowland blanket bogs, cutover blanket bogs, and poor fens and flushes. Although the poor fen and flushes did not have high overall richness of species or wet-associated species, a number of rare species were supported. Furthermore, along with the lowland blanket bogs they supported a distinct 
spider fauna from the other peatland plots which suggests that wet flushes may be important indicators of biodiversity value in peatlands. In contrast, the cutover bogs supported relatively few species and the lack of rare species suggests that they may be indicators of low biodiversity value within peatlands. The supplementary plots in the wet heaths supported fewer habitat specialists than the upland and lowland blanket bogs however this was due to the poor catches in the supplementary ditches within one site, which had recently been cleared of vegetation.

In the wet grasslands, moderate-high grazing intensity was an indicator of low overall spider diversity. In the improved grasslands there was a positive influence of the ground vegetation on the number of ground layer species, however the majority of these species was very common. Furthermore, the low biodiversity value of the improved grassland spider fauna in general may mean that variation in grazing regime or vegetation structure within this habitat may be of little consequence.

In the peatlands cover of ground vegetation was negatively associated with total species richness and richness of wetland species whereas these species variables were positively associated with lower field layer cover. This is unlikely to be due to habitat differences as the relationship between species richness and vegetation cover was unrelated to habitat type within the peatlands. It may, however, be related to differences in grazing regime within the sites. For instance, Dennis et al. (1998) found that overall spider richness as well as the abundances of L. mengei, A. olivacea and S. elegans (common species in the peatlands in the present study) were significantly higher in tussocks compared to swards in upland grasslands. A finding which they related to protection from grazing. This indicates that information on the management of a site will be a more useful indicator of biodiversity value than a survey of the vegetation structure present.

\section{Conclusions}


This study suggests that in terms of biodiversity value, improved grassland is the preferable habitat for afforestation. It may, however, be unrealistic to expect land owners to establish forest plantations solely on improved grassland, which is often the most fertile and productive agricultural land. Therefore future research should focus on developing management and habitat indicators to be of use when assessing habitat quality in the afforestation site selection process, most especially with regard to assessing features within sites which may be of high biodiversity value, such as wet flushes. This way, if habitats such as wet grassland and peatland are considered for afforestation then sites with lower biodiversity value, such as those with heavier grazing or cutover bogs, can be readily identified.

\section{Acknowledgements}

We would like to thank Julianna O'Callaghan and Maire Buckley for help with fieldwork and our colleagues on the BIOFOREST Project for useful comments on experimental design and the manuscript. We also thank Robert Johnston and Dr Peter Merrett for verifying the identification of several specimens. This work was carried as part of the BIOFOREST Project which is jointly funded by the Environmental Protection Agency and the National Council for Forest Research and Development (COFORD) through the National Development Plan of Ireland.

\section{References}

Berger, W. H., Parker, F. L., 1970. Diversity of planktibuc Foraminifera in deep sea sediments. Science 168, 1345-1347.

Bratton, J. H., 1991. British Red Data Books 3: Invertebrates Other Than Insects. Joint Nature Conservation Committee. 
Cardoso, P., Silva, I., de Oliveira, N. G., Serrano, A. R. M., 2004. Indicator taxa of spider (Araneae) diversity and their efficiency in conservation. Biol. Conserv. 120, 517-524.

Cattin, M., Blandenier, G., Banasek-Richter, C., Bersier, L., 2003. The impact of mowing as a management strategy for wet meadows on spider (Araneae) communities. Biol. Conserv. $113,179-188$.

Cawley, M., 2001. Distribution records for uncommon spiders (Araneae) including five species new to Ireland. Bull. Irish Biogeogr. Soc. 25, 135-143.

COFORD, 2000. Forecast of Roundwood Production from the Forests of Ireland 2001 - 2015.

COFORD, Dublin.

Cole, L., McCracken, D., Downie, I. S., Dennis, P., Foster, G., Waterhouse, T., Murphy, K., Griffin, A., Kennedy, M., 2003. Comparing the effects of farming practices on ground beetle (Coleoptera: Carabidae) and spider (Araneae) assemblages of Scottish farmland. Biodivers. Conserv. 14, 441-460.

Dennis, P., Young, M. R., Gordon, I., 1998. Distribution and abundance of small insects and arachnids in relation to structural heterogeneity of grazed, indigenous grasslands. Ecol. Entomol. 23, 253-264.

Dennis, P., Young, M. R., Bentley, C., 2001. The effect of varied grazing management on epigeal spiders, harvestmen and psuedoscorpions of Nardus stricta grassland in upland Scotland. Agric. Ecosyst. Environ. 86, 39-57.

Downie, I., Wilson, W., Abernethy, V., McCracken, D., Foster, G., Ribera, I., Murphy, K., Waterhouse, A., 1999. The impact of different agricultural land-uses on epigeal spider diversity in Scotland. J. Insect Conserv. 3, 273-286. 
Duelli, P., Obrist, M. K., 2003. Biodiversity indicators: the choice of values and measures. Agric. Ecosyst. Environ. 98, 87-98.

Dufrene, M., Legendre, P., 1997. Species assemblages and indicator species: the need for a flexible assymetric approach. Ecol. Monogr. 67, 345-366.

5 Fahy, O., Gormally, M., 2003. Two additions to the Irish spider fauna (Araneae, Linyphiidae): Walckenaeria dysderoides (Wider, 1834) and Agyneta ramosa (Jackson, 1912). Irish Nat. J. 27, 318-319.

Forest Service, 2004. Forestry statisics. http://www.agriculture.gov.ie/forestry/files/standard.xls. Department of Agriculture and Food, Dublin.

Fossitt, J., 2000. A Guide to Habitats in Ireland. The Heritage Council, Kilkenny.

Gravesen, E., 2000. Spiders (Araneae) and other invertebrate groups as ecological indicators in wetland areas. Ekol. Bratis. 19, 39-42.

Grimshaw, H. M., 1989. Analysis of soils. In: Grimshaw, H. M. (ed.), Chemical Analysis of Ecological Materials. Blackwell Scientific, Oxford, pp. 14-16.

Harvey, P., Nellist, D., Telfer, M., 2002. Provisional Atlas of British Spiders (Arachnida, Araneae), Volume 1 \& 2. Biological Records Centre, Huntingdon.

Kajak, A., Kupryjanowicz, J., Petrov, P., 2000. Long term changes in spider (Araneae) communities in natural and drained fens in the Biebrza River Valley. Ekol. Bratis. 19, 5564.

McCune, B., Mefford, M., 1997. PC-ORD for Windows. MjM Software, Oregon.

McFerran, D., 1997. Northern Ireland Species Inventory: Spiders (Arachnida). Queens University Belfast. 
Melbourne, B., 1999. Bias in the effect of habitat structure on pitfall traps: An experimental evaluation. Australian J. Ecol. 24, 228-239.

Mueller-Dombois, D., Ellenberg, H., 1974. Aims and Methods of Vegetation Ecology. Wiley and sons. New York.

Nolan, M., 2000a. A provisional list of spiders (Araneae) from Lesley Gibson's survey (1979 1982) of Carnsore point, Co. Wexford, including one new species to Ireland, Maro Minutus (O.P - Cambridge, 1906) (Linyphiidae). Irish Nat. J. 24, 159-167.

Nolan, M., 2002a. Spiders (Araneae) of montane blanket bog in county Wicklow, Ireland. Bull. Irish Biogeogr. Soc 26, 39-59.

Nolan, M., 2002b. Uncommonly recorded spiders (araneae) from Ireland, including one new species to the country. Bull. Irish Biogeogr. Soc 26, 154-160.

Paoletti, M., 1999. Using bioindicators based on diversity to assess landscape sustainability. Agric. Ecosys. Environ. 74, 1-18.

Roberts, M., 1993. The Spiders of Great Britain and Ireland. Part One. Harley Books, Colchester.

Rushton, S. P., Eyre, M. D., 1989. The spider fauna of intensively managed agricultural grasslands. J. Appl. Entomol. 108, 291-297.

SPSS, 2002. SPSS for Windows Version 11.0. SPSS, Chicago.

Teagasc: Irish agriculture food development authority, 2005. Agriculture in Ireland: http://teagasc.ie/. Teagasc, Carlow.

Toft, S., Lovei, G., 2000. The epigeic spider fauna of single-row hedges in a Danish agricultural landscape. In: Toft, S.Scharff N., (Eds). European Arachnology 2000 (19th European Colloqium of Arachnology). Aarhus University Press, Denmark. pp 237242. 
Uetz, G., 1991. Habitat Structure and Spider Foraging. In: Bell, S., McCoy, E., Mushinsky, H., (Eds.). Habitat structure: The Physical Arrangement of Objects in Space. Chapman and Hall, London.

UNECE, MCPFE Liason Unit Vienna, 2003. State of Europe's Forests 2003: The MCPFE's Report on Sustainable Forest Management in Europe. 4th Ministerial conference on the protection of forests in Europe. United Nations Economic Commission for Europe, Vienna.

Usher, M., 1992. Management and diversity of arthropods in Calluna heathland. Biodivers. Conserv. 1, 63-79.

van Helsdingen, P., 1996a. The county distrubution of Irish spiders. Irish Nat. J. Special Zoological Supplement.

van Helsdingen, P., 1996b. The spider fauna of some Irish flood plains. Irish Nat. J. 25, 285-293. van Helsdingen, P., 1997. The spiders (Areneida) of Pollardstown Fen, Co. Kildare, Ireland. Irish Nat. J. 25, 396-404. Weyman, G., Jepson, P., Sunderland, K., 1995. Do seasonal changes in numbers of aerially dispersing spiders reflect population density on the ground or variation in ballooning motivation? Oecologia 101, 487-493. 


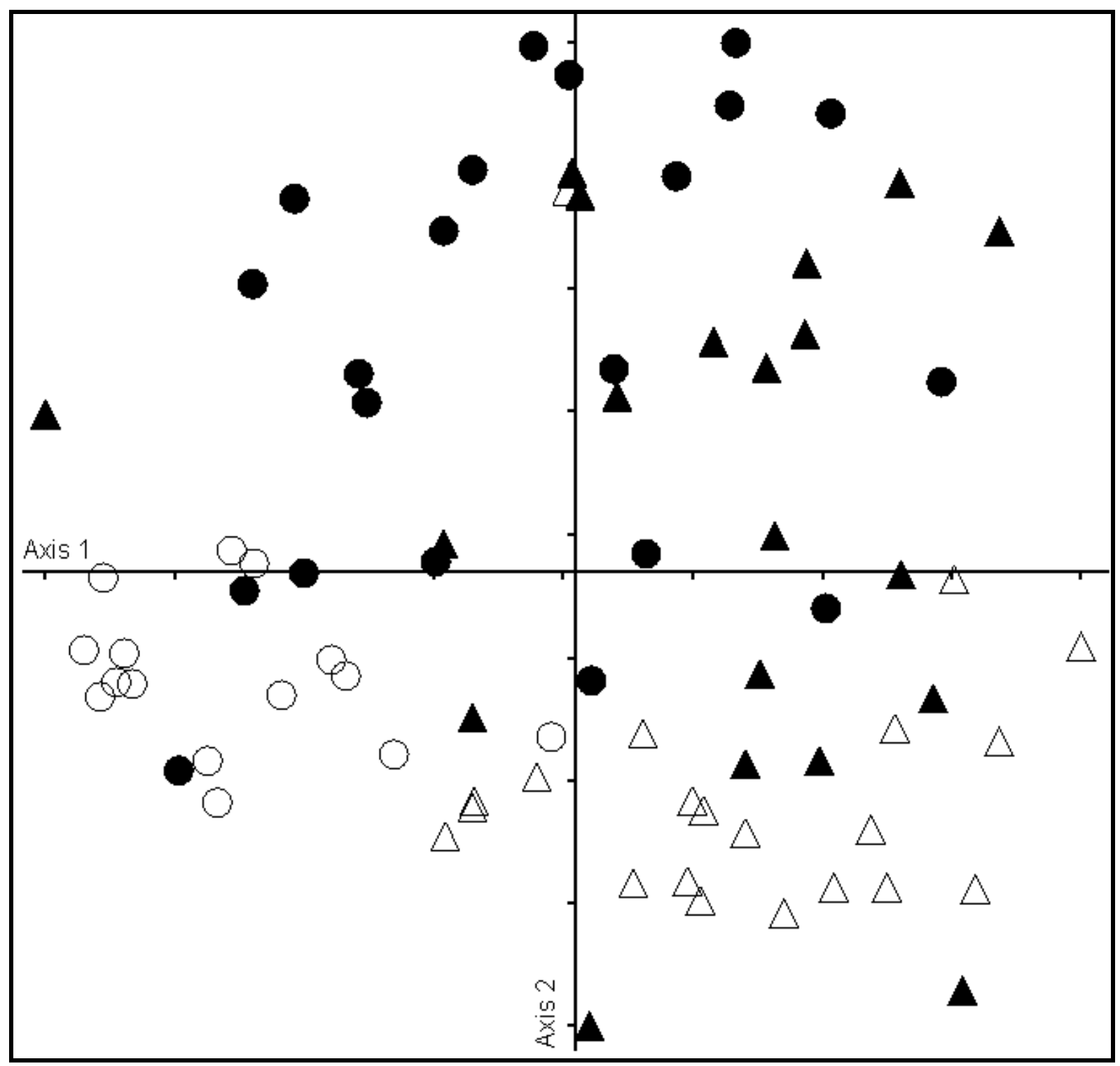

5 Fig.1. NMS ordination of spider assemblages among the grassland plots: Open triangle $=$ Wet grassland-standard; Closed triangle $=$ Wet grassland-supplementary; Open circle $=$ Improved grassland-standard; Closed circle $=$ Improved grassland-supplementary. Final stress $=14.01$; Final instability $=0.001$; Axis $1 \mathrm{r}^{2}=0.26$; Axis $2 \mathrm{r}^{2}=0.20$ 


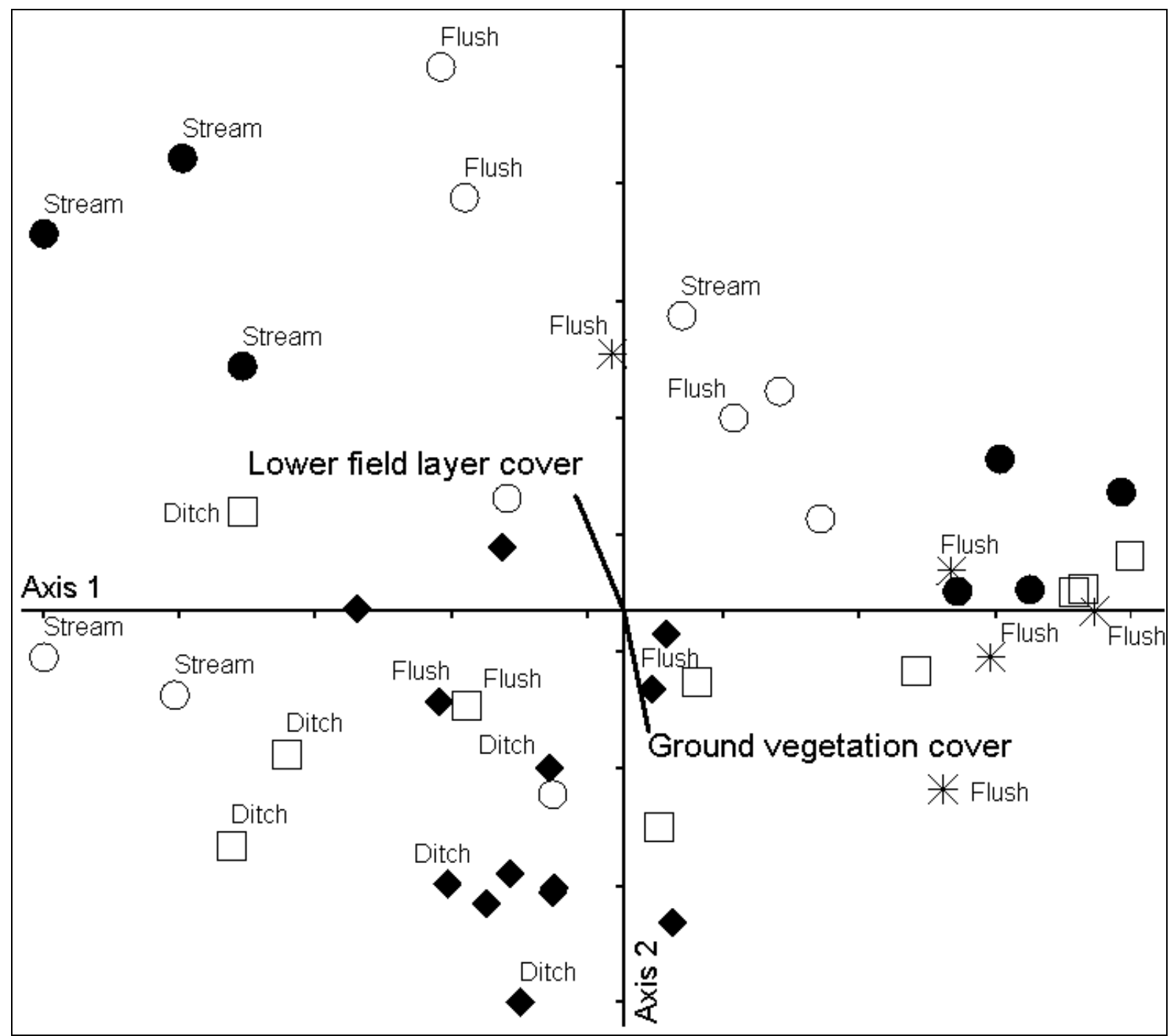

Fig.2. Joint biplot (NMS) of the spider assemblages among the peatland plots with the Irish habitat classifications (Fossitt, 2000): Closed diamond = Upland blanket bog; Closed circle $=$

5 Lowland blanket bog; Open square $=$ Wet heath; Open circle $=$ Cutover bog; Star $=$ Poor fen and flush. Habitat variables with Pearson correlation with $\mathrm{r}^{2}>0.1$ with the ordination axes are shown. Text adjacent to plot symbol denotes the type of supplementary plot sampled: Stream = edge of streams; Ditch $=$ edge of ditches; Flush. Standard plots are without text. Final stress $=13.07$; Final instability $=0.0004$; Axis $1 r^{2}=0.47$; Axis $2 r^{2}=0.18$. 
Table 1

Mean \pm SE species richness, abundance, dominance, and richness (S) of habitat specialists per site among the habitats and plot types (Standard and Supplementary). Results of the mixed model Two-way ANOVA and Tukey post-hoc tests with habitat and plot type as fixed factors and site as a random factor nested within habitat are shown, $\mathrm{F}$ values in bold type indicate those significant after Bonferroni correction.

\begin{tabular}{|c|c|c|c|c|c|c|c|c|c|}
\hline & \multicolumn{2}{|c|}{ Improved grassland } & \multicolumn{2}{|c|}{ Wet grassland } & \multicolumn{2}{|c|}{ Peatland } & \multicolumn{3}{|c|}{ ANOVA F } \\
\hline & $\begin{array}{l}\text { Standard } \\
(\mathrm{n}=6)\end{array}$ & $\begin{array}{l}\text { Supplementary } \\
(\mathrm{n}=6)\end{array}$ & $\begin{array}{l}\text { Standard } \\
(\mathrm{n}=8)\end{array}$ & $\begin{array}{l}\text { Supplementary } \\
(\mathrm{n}=8)\end{array}$ & $\begin{array}{l}\text { Standard } \\
(\mathrm{n}=5)\end{array}$ & $\begin{array}{l}\text { Supplementary } \\
(\mathrm{n}=5)\end{array}$ & $\begin{array}{l}\text { Habitat } \\
(\mathrm{df}=2,16)\end{array}$ & $\begin{array}{l}\text { Plot } \\
\left(\mathrm{df}={ }_{1,16}\right)\end{array}$ & $\begin{array}{l}\text { Interaction } \\
(\mathrm{df}=2,16)\end{array}$ \\
\hline Species richness & $16.9 \pm 1.8^{b}$ & $17.9 \pm 1.4^{b}$ & $23.0 \pm 2.5$ & $19.5 \pm 2.3$ & $26.8 \pm 1.8^{a}$ & $26.5 \pm 2.1^{\mathrm{a}}$ & $4.63^{*}$ & 0.95 & 2.06 \\
\hline Abundance & $51 \pm 9.2$ & $174 \pm 44$ & $191 \pm 36$ & $71 \pm 15$ & $174 \pm 59$ & $225 \pm 54$ & 1.72 & 0.75 & $14.3^{* * *}$ \\
\hline Berger-Parker & $0.22 \pm 0.02$ & $0.32 \pm 0.05$ & $0.34 \pm 0.04$ & $0.28 \pm 0.04$ & $0.23 \pm 0.05$ & $0.30 \pm 0.05$ & 0.66 & 1.74 & 3.28 \\
\hline Open-associated S & $7.6 \pm 0.7$ & $4.6 \pm 0.8$ & $7.7 \pm 0.8$ & $4.2 \pm 0.9$ & $6.8 \pm 0.9$ & $5.7 \pm 0.7$ & 0.96 & $39.3^{* * *}$ & 3.31 \\
\hline Forest-associated S & $0.5 \pm 0.2$ & $1.9 \pm 0.3$ & $0.5 \pm 0.1$ & $2.3 \pm 0.4$ & $0.5 \pm 0.2$ & $0.9 \pm 0.2$ & 0.17 & $26.0 * * *$ & 0.13 \\
\hline Wet-associated S & $6.8 \pm 0.6$ & $4.4 \pm 0.3$ & $8.9 \pm 0.1$ & $4.8 \pm 1.2$ & 8. \pm 1.4 & $8.5 \pm 1.0$ & 0.14 & $20.6^{* * *}$ & $4.95^{*}$ \\
\hline Ground layer-associated S & $9.8 \pm 1.0^{b}$ & $11.4 \pm 1.0^{b}$ & $15.0 \pm 1.6^{b}$ & $13.6 \pm 1.5^{b}$ & $19.4 \pm 1.4^{\mathrm{a}}$ & $19.4 \pm 1.6^{a}$ & $9.80 * * *$ & 0.93 & 0.22 \\
\hline Low vegetation-associated $\mathrm{S}$ & $1.6 \pm 0.3$ & $1.8 \pm 0.2$ & $2.7 \pm 0.6$ & $2.0 \pm 0.4$ & $3.1 \pm 0.4$ & $2.8 \pm 0.3$ & 0.11 & 0.27 & 0.23 \\
\hline
\end{tabular}

$5 \quad \mathrm{p}=<0.05 ;{ }^{* *} \mathrm{p}=<0.01 ;{ }^{* * *} \mathrm{p}=<0.001$

a denotes value is significantly greater than value marked with ${ }^{b}$ 
Table 2

Common and rare species among the cluster assemblage groups: a) Species with significant indicator values identified by Indicator Species Analysis (combination of relative abundance and relative frequency), the maximum indicator value and associated significance (Monte Carlo test) for each species are indicated by bold type. b) Number of individuals sampled for each of the rare species and the plot type they were

5 sampled in: $\mathrm{St}=$ Standard; Sup = Supplementary $(\mathrm{F}=$ Flush, $\mathrm{S}=$ Stream edge, $\mathrm{H}=$ Hedgerow $)$. The species habitat associations are also given: $\mathrm{O}$

$=$ associated with open habitats; $\mathrm{F}=$ associated with forested habitats; $\mathrm{W}=$ associated with wet habitats, $\mathrm{G}=$ habitat generalist, $\mathrm{S}=$ associated with shrub layer.

\begin{tabular}{|c|c|c|c|c|c|}
\hline & $\begin{array}{c}\text { Habitat } \\
\text { association }\end{array}$ & Peatland-Open & Linear & $\begin{array}{l}\text { Improved } \\
\text { grassland- } \\
\text { Open }\end{array}$ & $\begin{array}{c}\text { Wet } \\
\text { grassland }\end{array}$ \\
\hline a) Common species & & \multicolumn{4}{|c|}{ Percentage indicator value } \\
\hline Silometopus elegans (O. P.- Cambridge) & $\mathrm{O}, \mathrm{W}$ & $61 * * *$ & 1 & 0 & 0 \\
\hline Pirata piraticus (Clerck) & $\mathrm{O}, \mathrm{W}$ & $57 * * *$ & 0 & 1 & 13 \\
\hline Pardosa pullata (Clerck) & $\mathrm{O}$ & $56 * * *$ & 4 & 13 & 17 \\
\hline Agyneta olivacea (Emerton) & W & $44 * *$ & 3 & 0 & 0 \\
\hline Lepthyphantes mengei (Kulczynski) & $\mathrm{G}$ & $42 * * *$ & 6 & 0 & 3 \\
\hline Antistea elegans (Blackwall) & $\mathrm{O}, \mathrm{W}$ & $40 * * *$ & 0 & 0 & 4 \\
\hline Ceratinella brevipes (Westring) & $\mathrm{G}$ & $35 * *$ & 14 & 0 & 3 \\
\hline Pardosa nigriceps (Thorell) & $\mathrm{O}, \mathrm{G}$ & $35 * * *$ & 4 & 3 & 3 \\
\hline Trichopterna thorelli (Westring) & W & $33 * *$ & 0 & 0 & 0 \\
\hline Trochosa terricola (Thorell) & $\mathrm{G}$ & $30 * *$ & 4 & 1 & 11 \\
\hline Lepthyphantes zimmermanni (Bertkau) & $\mathrm{F}$ & 2 & $50 * *$ & 1 & 2 \\
\hline Monocephalus fuscipes (Blackwall) & $\mathrm{F}$ & 0 & $39 * * *$ & 0 & 14 \\
\hline Agyneta subtilis (O. P.- Cambridge) & G & 10 & $34 * *$ & 0 & 2 \\
\hline Dismodicus bifrons (Blackwall) & G & 2 & $34 * *$ & 6 & 15 \\
\hline Maso sundevalli (Westring,) & $\mathrm{G}$ & 3 & $30 * *$ & 1 & 4 \\
\hline Bathyphantes parvulus (Westring) & $\mathrm{G}$ & 4 & $33 * *$ & 1 & 11 \\
\hline Oedothorax fuscus (Blackwall) & $\mathrm{O}$ & 0 & 0 & $89 * * *$ & 3 \\
\hline Erigone dentipalpis (Wider) & $\mathrm{O}$ & 0 & 1 & 88*** & 0 \\
\hline
\end{tabular}


Pardosa palustris (Linnaeus)

Erigone atra (Blackwall)

Bathyphantes gracilis (Blackwall)

Pardosa amentata (Clerck)

Gnathonarium dentatum (Wider)

b) Rare species

Meioneta mollis (O. P.- Cambridge)

Nigma puella (Simon)

Zelotes lutetianus (Koch)

Satilatlas britenni (Jackson)

Maro sublestus (Falconer)

Baryphyma gowerense (Locket)

Saloca diceros (O. P.- Cambridge)

Milleriana inerrans (O. P.- Cambridge)

\begin{tabular}{|c|c|c|c|c|}
\hline $\mathrm{O}$ & 1 & 1 & $64 * * *$ & 4 \\
\hline $\mathrm{O}$ & 0 & 4 & $76 * * *$ & 6 \\
\hline $\mathrm{G}$ & 4 & 16 & $36 * *$ & 18 \\
\hline $\mathrm{O}, \mathrm{W}$ & 1 & 4 & 9 & $77 * * *$ \\
\hline $\mathrm{W}$ & 1 & 0 & 0 & $35 * * *$ \\
\hline & \multicolumn{4}{|c|}{ Number of individuals } \\
\hline $\mathrm{W}$ & 19 (Sup-F) & 0 & 0 & 0 \\
\hline $\mathrm{S}$ & $1(\mathrm{St})$ & 0 & 0 & 0 \\
\hline $\mathrm{O}$ & $1(\mathrm{St})$ & 0 & 0 & 0 \\
\hline $\mathrm{O}, \mathrm{W}$ & $76(\mathrm{St}), 3$ (Sup-F) & $1($ Sup-S) & 0 & 0 \\
\hline $\mathrm{W}$ & 0 & 2 (Sup-S) & 0 & 0 \\
\hline $\mathrm{O}, \mathrm{W}$ & 1 (Sup-F) & 0 & 0 & $4(\mathrm{St})$ \\
\hline $\mathrm{W}$ & 0 & 6 (Sup-H) & 0 & 0 \\
\hline $\mathrm{G}$ & 0 & 0 & 0 & $1(\mathrm{St})$ \\
\hline
\end{tabular}

$\mathrm{p}=<0.05 ;{ }^{* *} \mathrm{p}=<0.01 ;{ }^{* * *} \mathrm{p}=0.001$ 

Table 3

Mean \pm SE species richness, abundance, dominance and richness (S) of habitat specialists among the peatland plots as classified by the Irish

habitat categories (Fossitt, 2000). One-way ANOVA and Tukey post hoc tests among the habitat types are shown within each plot type: Standard,

df $=3,21 ;$ Supplementary df $=3,22$.

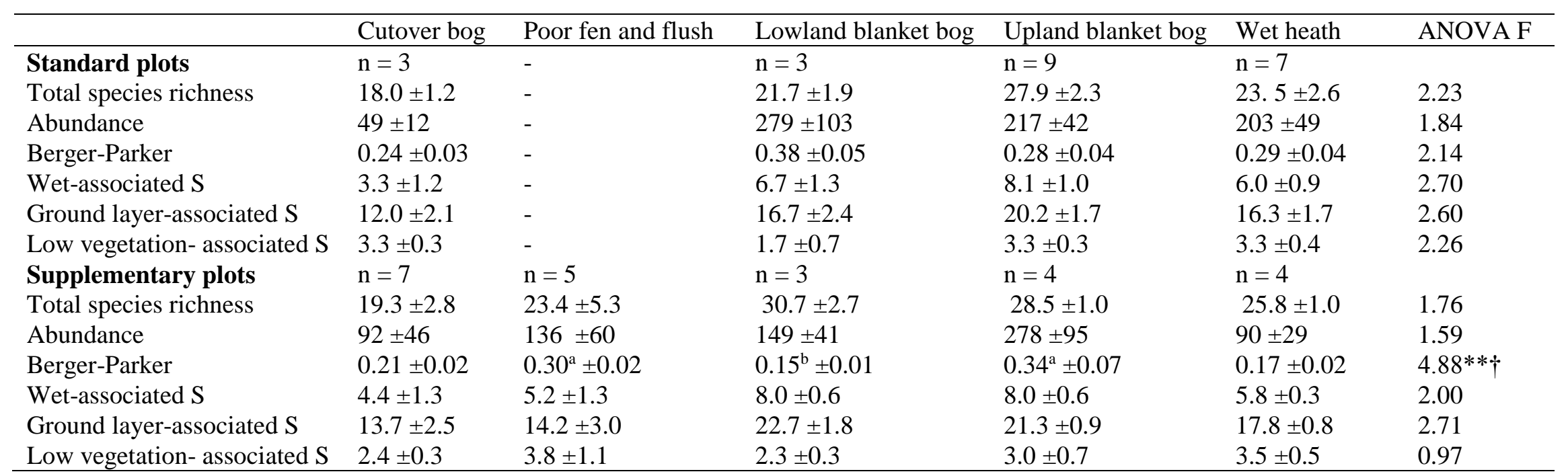

$5 * \mathrm{p}=<0.05 ; * * \mathrm{p}=<0.01$.

${ }^{\mathrm{a}}$ denotes value significantly greater than value marked with ${ }^{\mathrm{b}}$

$\uparrow$ Not significant after Bonferroni correction 
Table 4

Correlations (Pearson's r) between species variables and cover of habitat variables with significant $r$ values after Bonferroni correction indicated by bold type.

\begin{tabular}{lcccc}
\hline \multirow{2}{*}{ Species variable } & \multicolumn{4}{c}{ Habitat variable } \\
\cline { 2 - 5 } & $\begin{array}{c}\text { Ground } \\
\text { vegetation }\end{array}$ & $\begin{array}{c}\text { Lower-field } \\
\text { layer }\end{array}$ & $\begin{array}{c}\text { Upper-field } \\
\text { layer }\end{array}$ & Deadwood \\
\hline Peatland-Open $(\mathbf{n = 4 2})$ & $-0.38^{*}$ & $0.32^{*}$ & i.d & i.d \\
Species richness & $0.42^{* *}$ & $\mathbf{- 0 . 5 6} * * *$ & i.d & i.d \\
Abundance & 0.24 & $-0.39^{* *}$ & i.d & i.d \\
Berger-Parker & $-0.32^{*}$ & 0.18 & i.d & i.d \\
Wet-associated species & $-0.33^{*}$ & 0.28 & i.d & i.d \\
Ground layer associated species & & & & -0.09 \\
Linear $(\mathbf{n}=\mathbf{4 4})$ & -0.06 & 0.07 & $\mathbf{- 0 . 4 5 * *}$ & -0.14 \\
Species richness & 0.02 & 0.07 & $\mathbf{- 0 . 5 0} * * *$ & -0.01 \\
Abundance & -0.16 & 0.20 & 0.27 & $-0.30^{*}$ \\
Berger-Parker & -0.11 & $0.38^{*}$ & -0.23 & i.d \\
Wet-associated species & & & & i.d \\
Improved grassland-Open $(\mathbf{n}=\mathbf{2 0})$ & $0.46^{*}$ & -0.39 & & \\
Ground layer species & & & & i.d \\
Wet grassland $(\mathbf{n}=\mathbf{1 6})$ & $-0.59^{*}$ & $0.56^{*}$ & & \\
Low vegetation associated species & & &
\end{tabular}

5 i.d = Insufficient data 


\section{Table 5}

The mean \pm SE number of species, individuals, dominance and habitat specialist species among the standard plots in the wet grasslands divided into categories of grazing intensity. Results of ANOVA and Tukey post-hoc tests are shown with significant $\mathrm{F}$ values after Bonferroni correction indicated by bold type.

\begin{tabular}{|c|c|c|c|c|c|}
\hline & \multicolumn{4}{|c|}{ Grazing intensity } & \multirow{2}{*}{$\begin{array}{l}\text { ANOVA F } \\
(\mathrm{df}=3,20)\end{array}$} \\
\hline & Ungrazed $(n=6)$ & Light $(n=6)$ & Moderate $(n=5)$ & Heavy $(n=4)$ & \\
\hline Total species richness & $28.2 \pm 1.7^{\mathrm{a}}$ & $27.0 \pm 2.1^{\mathrm{a}}$ & $16.6 \pm 2.4^{\mathrm{b}}$ & $13.3 \pm 1.1^{\mathrm{b}}$ & $13.0 * * *$ \\
\hline Abundance & $221 \pm 23^{\mathrm{a}}$ & $261 \pm 43^{\mathrm{a}, \mathrm{c}}$ & $120 \pm 41^{\mathrm{d}}$ & $63 \pm 46^{b}$ & $6.0 * *$ \\
\hline Berger-Parker & $0.33 \pm 0.06$ & $0.43 \pm 0.10$ & $0.32 \pm 0.04$ & $0.30 \pm 0.04$ & 1.0 \\
\hline Open-associated species & $8.5 \pm 1.0$ & $9.0 \pm 0.7$ & $6.4 \pm 1.6$ & $5.5 \pm 0.5$ & 2.3 \\
\hline Wet-associated species & $6.2 \pm 0.5^{\text {a }}$ & $5.8 \pm 0.8^{\mathrm{a}}$ & $2.8 \pm 0.1^{\mathrm{b}}$ & $2.3 \pm 0.8^{b}$ & $6.9 * *$ \\
\hline Ground layer-associated species & $19.0 \pm 1.0^{\mathrm{a}}$ & $16.7 \pm 1.0^{\mathrm{a}}$ & $11.2 \pm 1.5^{b}$ & $8.8 \pm 0.5^{b}$ & $17.5 * * *$ \\
\hline Low vegetation-associated species & $3.3 \pm 0.8^{\mathrm{a}}$ & $4.2 \pm 0.6^{\mathrm{a}}$ & $1.4 \pm 0.4^{\mathrm{b}}$ & $0.5 \pm 0.5^{b}$ & $6.7 * *$ \\
\hline
\end{tabular}

$5 * \mathrm{p}=<0.05 ; * * \mathrm{p}=<0.01 ; * * * \mathrm{p}=<0.001$

${ }^{\mathrm{a}}$ denotes value significantly greater than value marked with ${ }^{\mathrm{b}}$

${ }^{\mathrm{c}}$ denotes value significantly greater than value marked with ${ }^{\mathrm{d}}$ 